\title{
Distal malignant biliary obstruction: a prospective randomised trial comparing plastic and uncovered self-expanding metal stents in the palliation of symptomatic jaundice
}

\author{
MM Bernon, ${ }^{1}$ J Shaw, ${ }^{2}$ S Burmeister, ${ }^{1}$ G Chinnery, ${ }^{1}$ S Hofmeyr, ${ }^{3}$ JC Kloppers, ${ }^{1}$ E Jonas, ${ }^{1}$ JEJ Krige, ${ }^{1}$ \\ ${ }^{1}$ Surgical Gastroenterology and HPB Surgical Unit Department of Surgery, University of Cape Town Health Sciences Faculty, \\ Groote Schuur Hospital, Anzio Road, Observatory 7925, Cape Town, South Africa \\ ${ }^{2}$ Hepatobiliary Surgery Unit, Division of General Surgery, University of Saskatchewan and Royal University Hospital, \\ Hospital Drive, Saskatoon, S7N 0W8, Saskatchewan, Canada \\ ${ }^{3}$ Department of Surgery, University of Stellenbosch, Health Sciences Faculty, Tygerberg Hospital, Parow, 7503, Cape Town, \\ South Africa
}

Corresponding author: MM Bernon (marcbernon@mail.com)

\begin{abstract}
Background: The aim of this study was to determine the safety and clinical effectiveness of 10Fr plastic biliary stents compared to uncovered self-expanding metal stents (SEMS) for palliative treatment of patients with inoperable extra-hepatic malignant biliary obstruction in a public hospital in South Africa.

Methods: From January 2009 to December 2013, 40 patients who were admitted to a tertiary academic centre because of distal malignant biliary obstruction were enrolled in a prospective randomized study. Patients were randomly assigned to receive an uncovered SEMS or a plastic stent deployed through the biliary stricture during endoscopic retrograde cholangiopancreatography (ERCP).

Results: Patient survival time in the two groups did not differ significantly (median: SEMS - 114 days; plastic - 107 days). Stent failure was more common in the plastic stent group (7/19 vs. 1/21). The results became significant after 6 months of follow-up. There was no significant difference between the two groups in the incidence of serious adverse events.

Conclusions: SEMS had a longer duration of patency than plastic stents, which recommends their use in the palliative treatment of patients with biliary obstruction due to distal malignant biliary obstruction.
\end{abstract}

S Afr J Surg 2018;56(1)

$\underline{\text { http://dx.doi.org/10.17159/2078-5151/2018/v56n1a2208 }}$

\section{Introduction}

Tumours causing distal malignant biliary obstruction may arise in the head of the pancreas, duodenum, ampulla or distal common bile duct. Pancreatic cancers account for about two thirds of these cases, followed by ampullary cancers (about $20 \%$ ) and distal cholangiocarcinomas (15\%). Eighty percent of patients who present with distal malignant biliary obstruction are not candidates for surgical resection and require palliative treatment. ${ }^{1}$ Endoscopic biliary stenting has become the preferred method for relieving obstructive jaundice in these patients. $^{2}$ There have been significant advances in stent technology since the first plastic endoscopic biliary stent was placed in 1979. ${ }^{3}$ A major improvement was the development of self-expanding metal stents (SEMS). Initially SEMS were uncovered but there are now also commercially available fully covered and partially covered SEMS. There have been a number of studies comparing plastic stents to SEMS, but no such studies have been performed in an African institution. ${ }^{4-9}$ The studies that have been conducted have consistently shown that plastic stents have a higher occlusion rate and shorter patency compared to SEMS. Plastic stents do have some advantages over SEMS. They are cheaper and are easily removable, as opposed to in particular non-covered SEMS. The aim of this study was to determine the safety and clinical effectiveness of 10Fr plastic biliary stents compared to uncovered SEMS for palliative treatment of patients with inoperable but non-metastasized periampullary malignant biliary obstruction in a public hospital in South Africa.

\section{Patients and methods}

Between January 2009 and December 2013, eligble patients with symptomatic jaundice due to irresectable periampullary cancer were randomised to either a $10 \mathrm{Fr}$ plastic stent or an 
uncovered SEMS. The inclusion and exclusion criteria are shown in Table 1. Randomisation was on a 1:1 basis, using computer generated numbers placed in opaque envelopes. Patients were randomised once a guidewire had successfully been positioned across the stricture during endoscopic retrograde cholangiopancreatography (ERCP). A standard polyethylene plastic stent (Boston Scientific, MA, USA) with proximal and distal flanges or an uncovered SEMS (Boston Scientific, MA, USA) with $10 \mathrm{~mm}$ diameter were used. A plastic stent cost R 1437.86 and a metal stent cost R 6422.28 (prices in 2013). The lengths of the stents were chosen according to the extent of the stricture. Adhering to the CONSORT criteria, all patients presenting with periampullary carcinoma were entered in a database. Patients were evaluated with US, CT and/or MRI and reviewed at a MDT meeting to assess resectability.

Table 1. Inclusion and exclusion criteria

\begin{tabular}{|c|c|}
\hline Inclusion Criteria & Exclusion Criteria \\
\hline \multirow{3}{*}{$\begin{array}{l}\text { Clinical data suggestive of } \\
\text { a distal malignant bile duct } \\
\text { obstruction. }\end{array}$} & Metastatic disease \\
\hline & Resectable patients \\
\hline & Previous gastric surgery \\
\hline 18 years of age or older & or duodenal obstruction \\
\hline \multirow{2}{*}{$\begin{array}{l}\text { Information given and informed } \\
\text { consent obtained }\end{array}$} & preventing ERCP \\
\hline & Previous inclusion in the study \\
\hline $\begin{array}{l}\text { Bilirubin }>50 \text { umol/L (normal } \\
26 \text { umol/L) }\end{array}$ & $\begin{array}{l}\text { Participation in another clinical } \\
\text { trial in the preceding } 90 \text { days }\end{array}$ \\
\hline \multicolumn{2}{|c|}{$\begin{array}{l}\text { Typical radiological appearance } \\
\text { of malignant common bile duct } \\
\text { stenosis at ERCP }\end{array}$} \\
\hline \multicolumn{2}{|l|}{$\begin{array}{l}\text { Proximal margin of malignant } \\
\text { bile duct stenosis }>2 \mathrm{~cm} \text { from } \\
\text { the hepatic confluence }\end{array}$} \\
\hline ECOG* performance status $0-2$ & \\
\hline
\end{tabular}

Demographic and clinical data, post-procedural duration of hospital stay, complications and need for any additional interventions were documented. Patients were followed up monthly until the time of death or up to 12 months. At followup liver function tests were performed in patients with a clinical suspicion of stent dysfunction. Re-interventions were documented. For patients with stent dysfunction the salvage strategy was left to the treating endoscopist. Any hospital readmissions were recorded, specifying the indication for admission.

The primary endpoint in the study was effective palliation of biliary obstruction, defined as a functioning stent at time of death or at 12 months.

Secondary endpoints included ability to safely deploy the stent in a satisfactory position, procedure-related adverse events and the need for re-intervention. Ethical approval for the trial and the registries from which data was extracted were obtained from the University of Cape Town Human Research Ethics Committee.

\section{Statistical analysis}

Descriptive statistics as appropriate were used to present clinical and treatment characteristics and outcome of the study subjects. The Fisher exact test and Student's t-test (unpaired) were used to assess differences between the two groups. The Kaplan-Meier method was used to estimate survival time and probabilities for survival and stent patency times. The censored events for stent patency were loss to follow-up, death, or patency after 1 year of follow-up. Censored events for survival were lost to follow-up. Differences in survival and stent patency probabilities were calculated with the log-rank test using Stata (version 13.1; Stata Corp, College Station, Texas, USA). A $p<0.05$ was considered statistically significant where appropriate.

Table 2. Patient demographic and clinical characteristics at inclusion

\begin{tabular}{|c|c|c|c|c|}
\hline & & Plastic Stent & SEMS & p-value \\
\hline No of Patients n (\%) & & $19(47.5 \%)$ & $21(52.5 \%)$ & \\
\hline Males/Females & & $8 / 11$ & $9 / 12$ & $\mathrm{p}=0.61$ \\
\hline Median Age (IQR)* & & $65(60-80)$ & $69.5(59.5-74)$ & $\mathrm{p}=0.68$ \\
\hline \multirow[t]{6}{*}{ Performance status(ECOG) } & 0 & 0 & $1(4.8 \%)$ & $\mathrm{p}=0.520$ \\
\hline & 1 & $4(21.1 \%)$ & $5(23.8 \%)$ & $\mathrm{p}=0.569$ \\
\hline & 2 & $15(78.9 \%)$ & $15(71.4 \%)$ & $\mathrm{p}=0.4291$ \\
\hline & 3 & 0 & 0 & \\
\hline & 4 & 0 & 0 & \\
\hline & 5 & 0 & 0 & \\
\hline Pancreatic cancer & & 17 & 18 & $\mathrm{p}=0.5494$ \\
\hline Cholangiocarcinoma & & 2 & 3 & \\
\hline Median tumour size $\mathrm{cm}$ (range) & & $3.0(1.0-4.9)$ & $3.0(2.0-6.8)$ & $p=0.55$ \\
\hline Median Bilirubin umol/l (range) & & $338(71-651)$ & $357(40-681)$ & $\mathrm{p}=0.66$ \\
\hline Median Ca-19.9 U/ml (range) & & $392(1->1000)$ & $256(16->1000)$ & $\mathrm{p}=0.43$ \\
\hline
\end{tabular}




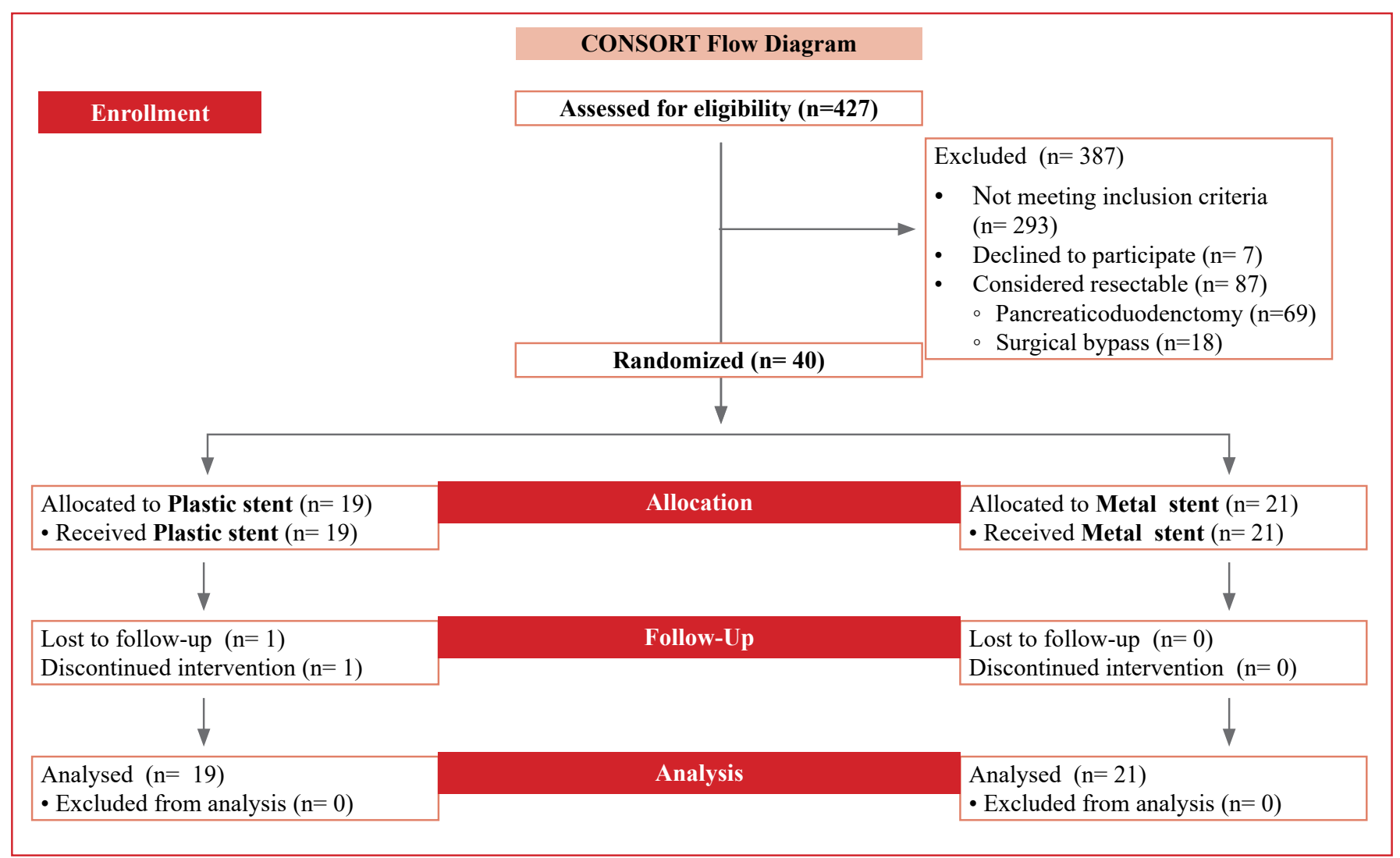

Figure 1

\section{Results}

A CONSORT flow diagram illustrating the inclusion of patients is shown in Figure 1. Forty patients were randomised. The demographic and clinical characteristics of the patients are summarised in Table 2 which showed no significant differences between groups. The intention to treat cohort included 17 men and 23 women, with a median age of 68 years (range 50-85). Thirty-six patients had pancreatic cancer and 4 had distal cholangiocarcinoma.

\section{Follow-up}

Patients were followed up until death or for 12 months. In the plastic stent group one patient was lost to follow-up after three months and another withdrew consent. These patients were included in the final intention to treat analysis.

\section{Survival}

Median survival in the two groups was similar as assessed by the Kaplan-Meier method and the log-rank test $(\mathrm{p}=0.18)$ (Figure 2). Thirty four patients (85\%) died during the study period, 15 in the plastic stent group and 19 in the SEMS group. The median survival in the SEMS group was 114 days compared to 107 days in the plastic stent group.

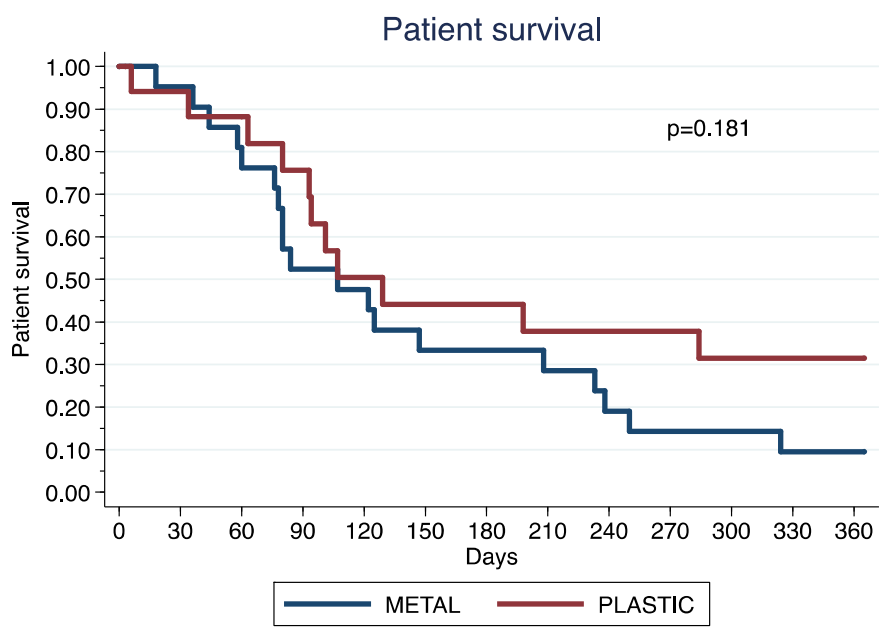

Figure 2. Kaplan Meier Graph comparing survival in the two groups

\section{Stent patency}

There was a significant difference in stent patency $(\mathrm{p}=0.043)$ with one of the SEMS (4.7\%) and seven of the plastic stents (38.8\%) occluding during the study period. The patient with the blocked SEMS had a stone above the malignant stricture that impacted in the stent 3 days after placement. The difference in stent patency became significant after six months (Table 3, Figure 3). The plastic stents had 25\% failure at 60 days and $50 \%$ failure at 351 days. 


\begin{tabular}{|c|c|c|c|}
\hline & Plastic & Metal & p value \\
\hline $\begin{array}{l}\text { Discharge from } \\
\text { hospital } \\
\text { (blocked/alive) }\end{array}$ & $0 / 19$ & $1 / 21$ & 1.0 \\
\hline $\begin{array}{l}\text { At } 1 \text { month } \\
\text { (blocked/alive) }\end{array}$ & $2 / 15$ & $1 / 20$ & 0.65 \\
\hline $\begin{array}{l}\text { At } 3 \text { months } \\
\text { (blocked/alive) }\end{array}$ & $3 / 11$ & $1 / 11$ & 0.3306 \\
\hline $\begin{array}{l}\text { At } 6 \text { months } \\
\text { (blocked/alive) }\end{array}$ & $6 / 7$ & $1 / 7$ & 0.0395 \\
\hline $\begin{array}{l}\text { At } 9 \text { months } \\
\text { (blocked/alive) }\end{array}$ & $6 / 5$ & $1 / 3$ & 0.0395 \\
\hline $\begin{array}{l}\text { At } 12 \text { months } \\
\text { (blocked/alive) }\end{array}$ & $7 / 4$ & $1 / 2$ & 0.0174 \\
\hline
\end{tabular}

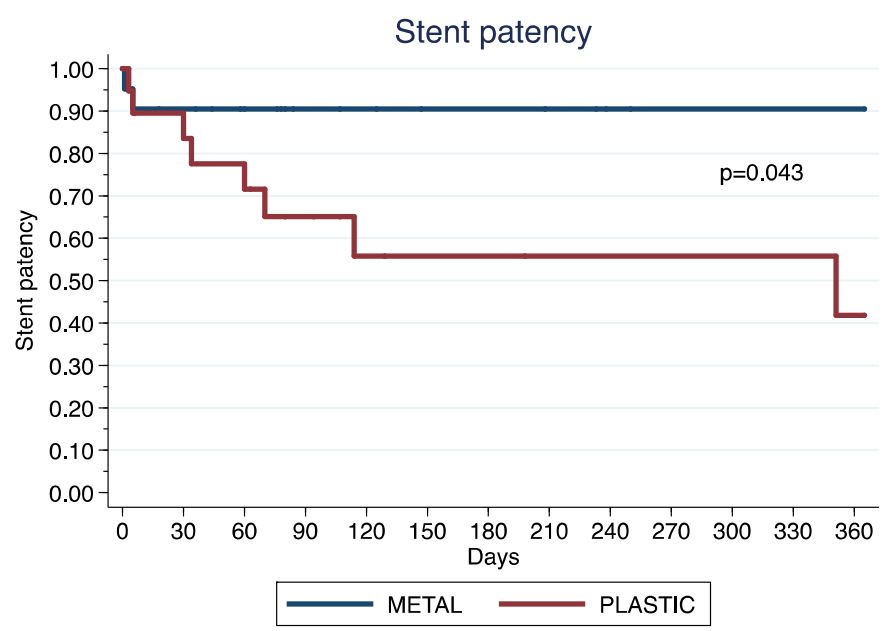

Figure 3. Kaplan Meier Graph comparing stent patency in the two groups

\section{Stent deployment and complications}

All patients had successful stent deployment and there were no ERCP-related complications. There were no unanticipated adverse device effects, and no deaths were attributed to the investigational device. In two patients (one in each group) jaundice did not subside despite patent stents. The cause of the prolonged cholestasis could not be ascertained. Four of the seven patients with blocked plastic stents presented with cholangitis. One patient in each group developed gastric outlet obstruction. They were both treated with an uncovered duodenal SEMS. One patient in the SEMS group was admitted with a bleeding gastric ulcer. Seven patients in the plastic stent group spent a total of 44 days in hospital with stent related complications compared to one patient in the SEMS group who was hospitalised for 21 days. None of the patients developed cholecystitis or pancreatitis.

\section{Discussion}

This is the first randomised control trial from an African institution that compares uncovered SEMS with traditional plastic stents for the endoscopic palliation of jaundice in patients with periampullary tumours. The findings in the study were in keeping with previously reported results, comparing uncovered SEMS and plastic stents, showing a lower incidence of stent dysfunction and longer stent patency in the SEMS groups. ${ }^{4-9}$ However, the improvement in stent patency comes at a considerable expense, with SEMS being up to 10 times more expensive than plastic stents. These costs are offset by the increased need for re-intervention in patients with stent dysfunction. ${ }^{10,11}$ In this study the difference became significant after six months of follow-up. Although the study did not address the cost effectiveness of SEMS it has been shown that SEMS are more cost effective in patients with a longer projected survival. ${ }^{10}$ Follow-up of patients in our patient population can be challenging. In spite of this, only one patient was lost to follow-up. In our healthcare environment, some patients who reside in rural areas have poor access to health facilities. These patients often experience considerable delays in getting appropriate treatment when they develop stent dysfunction. Increased use of SEMS in these patients is particularly useful.

There have been a number of randomised control trials comparing different types of SEMS (covered, partially covered, uncovered) and one randomised control trial comparing covered SEMS and plastic stents. Although the reason for stent failure differs with the different types of SEMS (ingrowth in uncovered SEMS vs. migration in covered SEMS), patency rates are similar. ${ }^{12-18}$ As the intention of the trial was to test the stents in patients with a life expectancy over six months only patients without metastatic disease and a good performance status (ECOG 0-2) were included. The strict inclusion criteria resulted in a long enrolment period and was the main reason for the small number of patients included in the study.

None of the patients in this study had a tissue diagnosis or received palliative chemotherapy. The diagnosis of malignancy was based on the clinical presentation and cross sectional imaging. With improved access to endoscopic ultrasound we now more frequently attempt to get a tissue diagnosis and a greater proportion of patients are receiving palliative chemotherapy.

Multiple plastic stents are frequently used to treat patients with benign strictures and have been shown to have better patency rates than single plastic stents. It has been suggested that multiple plastic stents may have a stent patency similar to SEMS in malignant strictures. ${ }^{19}$ There has not been a randomised trial comparing multiple plastic stents to SEMS. Two or three plastic stents are still considerably cheaper than a SEMS.

In order to ensure that SEMS are used in the most cost effective manner, further investigation is required to determine which patients are least likely to benefit from SEMS. Novel stenting strategies such as the use of multiple plastic stents in malignant strictures also need to be studied. 


\section{Acknowledgments}

We thank Kathryn Manning from the Division of General Surgery, University of Cape Town for help with the statistical analysis in this study.

\section{REFERENCES}

1. Yeo CJ, Cameron JL, Sohn TA, et al. Six hundred fifty consecutive pancreaticoduodenectomies in the 1990s: Pathology, complications, and outcomes. Ann Surg. 1997;226(3):248-57; discussion 257-60. Available from: http:// dx.doi.org/10.1097/00000658-199709000-00004

2. Taylor MC, McLeod RS, Langer B. Biliary stenting versus bypass surgery for the palliation of malignant distal bile duct obstruction: A meta-analysis. Liver Transpl. 2000;6(3):302-8. Available from: http://dx.doi.org/10.1053/lv.2000.5196

3. Soehendra N, Reynders-Frederix V. Palliative bile duct drainage - a new endoscopic method of introducing a transpapillary drain. Endoscopy. 1980;12(1):8-11. Available from: http:// dx.doi.org/10.1055/s-2007-1021702

4. Davids PH, Groen AK, Rauws EA, Tytgat GN, Huibregtse K. Randomised trial of self-expanding metal stents versus polyethylene stents for distal malignant biliary obstruction. Lancet. 1992;340(8834-8835):1488-92. Available from: http:// dx.doi.org/10.1016/0140-6736(92)92752-2

5. Knyrim K, Wagner HJ, Pausch J, Vakil N. A prospective, randomized, controlled trial of metal stents for malignant obstruction of the common bile duct. Endoscopy. 1993;25(3):207-12. Available from: http://dx.doi. org/10.1055/s-2007-1010294

6. Prat $\mathrm{F}$, Chapat $\mathrm{O}$, Ducot $\mathrm{B}$, et al. A randomized trial of endoscopic drainage methods for inoperable malignant strictures of the common bile duct. Gastrointest Endosc. 1998;47(1):1-7. Available from: http://dx.doi.org/10.1016/ S0016-5107(98)70291-3

7. Kaassis M, Boyer J, Dumas R, et al. Plastic or metal stents for malignant stricture of the common bile duct? results of a randomized prospective study. Gastrointest Endosc. 2003;57(2):178-82. Available from: http://dx.doi.org/10.1067/ mge.2003.66

8. Katsinelos P, Paikos D, Kountouras J, et al. Tannenbaum and metal stents in the palliative treatment of malignant distal bile duct obstruction: A comparative study of patency and cost effectiveness. Surg Endosc. 2006;20(10):1587-93. Available from: http://dx.doi.org/10.1007/s00464-005-0778-1

9. Soderlund C, Linder S. Covered metal versus plastic stents for malignant common bile duct stenosis: A prospective, randomized, controlled trial. Gastrointest Endosc. 2006;63(7):986-95. Available from: http://dx.doi.org/10.1016/j. gie.2005.11.052

10. Yeoh KG, Zimmerman MJ, Cunningham JT, Cotton PB.
Comparative costs of metal versus plastic biliary stent strategies for malignant obstructive jaundice by decision analysis. Gastrointest Endosc. 1999;49(4 Pt 1):466-71. Available from: http://dx.doi.org/10.1016/S0016-5107(99)70044-1

11. Wilcox CM, Kim H, Seay T, Varadarajulu S. Choice of plastic or metal stent for patients with jaundice with pancreaticobiliary malignancy using simple clinical tools: A prospective evaluation. BMJ Open Gastroenterol. 2015;2(1):e00014. Available from: http://dx.doi.org/10.1136/bmjgast-2014-000014

12. Telford JJ, Carr-Locke DL, Baron TH, et al. A randomized trial comparing uncovered and partially covered self-expandable metal stents in the palliation of distal malignant biliary obstruction. Gastrointest Endosc. 2010;72(5):907-14. Available from: http://dx.doi.org/10.1016/j.gie.2010.08.021

13. Kullman E, Frozanpor F, Soderlund C, et al. Covered versus uncovered self-expandable nitinol stents in the palliative treatment of malignant distal biliary obstruction: Results from a randomized, multicenter study. Gastrointest Endosc. 2010;72(5):915-23. Available from: http://dx.doi.org/10.1016/j. gie.2010.07.036

14. Almadi MA, Barkun AN, Martel M. No benefit of covered vs uncovered self-expandable metal stents in patients with malignant distal biliary obstruction: A meta-analysis. Clin Gastroenterol Hepatol. 2013;11(1):27-37.e1. Available from: http://dx.doi.org/10.1016/j.cgh.2012.10.019

15. Ung KA, Stotzer PO, Nilsson A, Gustavsson ML, Johnsson E. Covered and uncovered self-expandable metallic hanarostents are equally efficacious in the drainage of extrahepatic malignant strictures. results of a double-blind randomized study. Scand J Gastroenterol. 2013;48(4):459-65. Available from: http://dx.doi. org/10.3109/00365521.2012.758766

16. Lee SJ, Kim MD, Lee MS, et al. Comparison of the efficacy of covered versus uncovered metallic stents in treating inoperable malignant common bile duct obstruction: A randomized trial. J Vasc Interv Radiol. 2014;25(12):1912-20. Available from: http://dx.doi.org/10.1016/j.jvir.2014.05.021

17. Saleem A, Leggett CL, Murad MH, Baron TH. Meta-analysis of randomized trials comparing the patency of covered and uncovered self-expandable metal stents for palliation of distal malignant bile duct obstruction. Gastrointest Endosc. 2011;74(2):321-7.e1-3. Available from: http://dx.doi. org/10.1016/j.gie.2011.03.1249

18. Moole H, Bechtold ML, Cashman M, et al. Covered versus uncovered self-expandable metal stents for malignant biliary strictures: A meta-analysis and systematic review. Indian J Gastroenterol. 2016;35(5):323-30.

19. Lawrence C, Romagnuolo J. Double plastic stents for distal malignant biliary obstruction: Preliminary evidence for a novel cost-effective alternative to metal stenting. Am J Gastroenterol. 2014;109(2):295-7. Available from: http://dx.doi.org/10.1038/ ajg.2013.409 